\title{
Design, Modeling, and Analysis of a Brushless Doubly Fed Doubly Salient Machine for Electric Vehicles
}

\author{
Ying Fan, Member, IEEE, and K. T. Chau, Senior Member, IEEE
}

\begin{abstract}
This paper presents a new three-phase 12/8-pole brushless doubly fed doubly salient (BDFDS) machine for application to electric vehicles. It consists of two types of stator windings-polyphase armature winding and de field winding. The key is to design, model, and analyze the proposed BDFDS machine. The output power equation is derived analytically, and the initial calculation of machine dimensions and parameters are also discussed. When we use finite-element analysis, the field distributions of the BDFDS machine at different loads and field currents are obtained, in which magnetic saturation and armature reaction are considered. Static characteristics of the proposed machine are also obtained. Based on these characteristics, the system mathematical model can be established. Hence, the evaluation of system performance is conducted by computer simulation. A 12/8-pole BDFDS machine is designed and built for experimentation. Experimental results are given to verify the theoretical analysis and simulation.
\end{abstract}

Index Terms-Brushless machines, doubly salient motors, electric vehicles.

\section{INTRODUCTION}

W ITH ever-increasing concerns about our environment, the development of electric vehicles (EVs) has taken on an accelerated pace. To enable EVs directly competing with gasoline vehicles, our goals of the EV motor drive are to pursue high efficiency over a wide speed range, high power density, high controllability, high reliability, and maintenance-free operation [1]. The torque-speed characteristics of dc motors are attractive for EV propulsion. But, owing to the drawbacks of low efficiency, low power density as well as the need of mechanical commutator and carbon brushes, dc motors are superseded by induction motors [2], permanent-magnet brushless (PMBL) motors [3]-[6] and switched reluctance (SR) motors [7], [8]. Moreover, the doubly salient permanent magnet (DSPM) motor has recently been proposed, which combines the advantageous features of both PMBL and SR motors [9]-[12]. Nevertheless,

Paper IPCSD-07-096, presented at the 2005 Industry Applications Society Annual Meeting, Hong Kong, October 2-6, and approved for publication in the IEEE TRANSACTIONS ON INDUSTRY APPLICATIONS by the Electric Machines Committee of the IEEE Industry Applications Society. Manuscript submitted for review October 19, 2006 and released for publication October 17, 2007. This work was supported by a grant (Project HKU7114/06E) from the Research Grants Council of Hong Kong Special Administrative Region, China.

Y. Fan is with the School of Electrical Engineering, Southeast University, Nanjing 210096, China (e-mail: vickifan@ seu.edu.cn).

K. T. Chau is with the Department of Electrical and Electronic Engineering, The University of Hong Kong, Hong Kong, China (e-mail: ktchau@eee. hku.hk).

Digital Object Identifier 10.1109/TIA.2008.921406 the DSPM motor still suffers from drawbacks similar to that of the PMBL motors-the uncontrollable PM flux for high-speed operation and high PM cost.

Previous researches in the DSPM motor have suggested that the PM excitation can be directly replaced by a dc field winding [9]-[12]. Based on this idea, the new machine will consist of two types of stator windings - the polyphase armature winding and the dc field winding, so-called the brushless doubly fed doubly salient (BDFDS) machine. Because the dc current flowing through the field winding can be independently controlled, the BDFDS machine will not only solve the problem of the DSPM motor but also will offer the possibility to optimize the efficiency online.

The purpose of this paper is to design and analyze a threephase 12/8-pole BDFDS machine for EVs. Section II will give a brief introduction of the BDFDS machine. The theoretical equations and design procedure are described in Section III. Section IV discusses electromagnetic analysis and system modeling. The finite element analysis will be applied to analyze the static characteristics of the machine, in which both magnetic saturation and armature reaction are considered. In Section V, computer simulation of the whole drive system is discussed. The implementation and experimental verification is given in Section VI. Finally, conclusions are drawn in Section VII.

\section{Machine Description AND OPERATING PRinciples}

Fig. 1(a) depicts a three-phase 12/8-pole BDFDS machine, which consists of both dc field winding and three-phase concentrated armature winding in the stator, and solid iron core in the rotor. It has a similar structure to the SR motor with 12 salient poles in the stator and 8 salient poles in the rotor. Because there are no PMs, no brushes, and no windings in the rotor, it offers a very simple rotor structure and the capability to run at very high speed.

Compared with the SR motor, the BDFDS machine offers higher torque density because it possesses two torque producing zones-it can produce torque by applying either a positive current to the phase winding when the flux linkage is increasing or a negative current to the winding when the flux linkage is decreasing. Also, because the BDFDS machine has two kinds of stator windings - the polyphase armature winding and dc field winding - it can offer independent flux control for constantpower operation and efficiency-optimizing operation, which cannot be easily handled by the SR motor. 


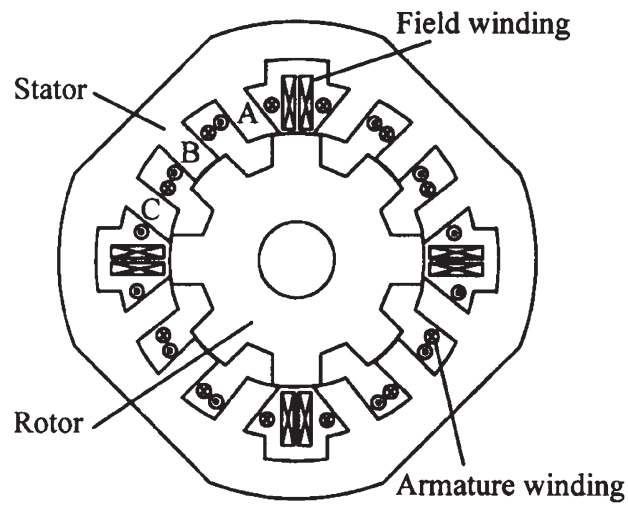

(a)

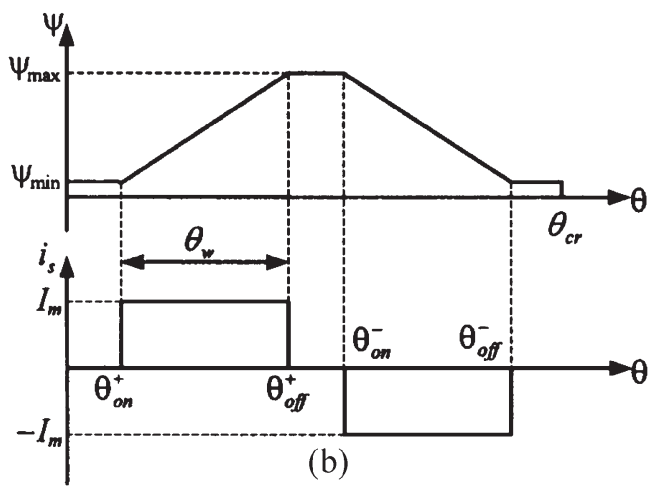

Fig. 1. Three-phase 12/8-pole BDFDS machine. (a) Configuration. (b) Operating principle.

The ideal operating waveforms of the flux linkage $\psi$ and phase current $i_{s}$ with respect to the rotor position $\theta$ are shown in Fig. 1(b). When the rotor pole is entering the zone of a conductive phase, the flux of the armature winding is increasing. When we apply a positive current to the winding, a positive torque is produced. When the rotor pole is leaving the stator pole from the aligned position, the flux is decreasing. By applying a negative current, a positive torque is also produced. Therefore, two possible torque-producing zones are used.

Note that during high-speed operation, the positive current may not be able to reach its steady-state value before the armature winding is switched off at the proper rotor position angle, whereas the negative current may quickly reach its steadystate value. Thus, the positive and negative currents need to be limited by using angle position control and current chopping control, respectively.

\section{THEORY}

\section{A. Equations}

Similar to the DSPM machine [11], [12], the output power $P_{o}$ of the BDFDS machine can be deduced as follows:

$$
P_{o}=\frac{0.87 \pi^{2}}{120} \frac{N_{r}}{N_{s}} k_{d} k_{e} k_{i} A_{s} B_{\delta} n_{s} \eta D_{i s}^{2} l_{e f}
$$

where $P_{o}$ is the output power; $N_{s}$ and $N_{r}$ are the stator and rotor pole numbers, respectively; $k_{d}$ is the flux leakage factor; $k_{e}=U / E$ is the ratio of voltage to back electromotive force (EMF); $k_{i}$ is the ratio of current amplitude $I_{m}$ to rms value of current $I_{\mathrm{rms}} ; A_{s}$ is the electric loading of stator, which can be chosen in the range of $100 \sim 300 \mathrm{~A} / \mathrm{cm} ; B_{\delta}$ is the air-gap flux density, which is usually selected as $1.5 \mathrm{~T} ; n_{s}$ is the rated speed; $\eta$ is the machine efficiency; $D_{i s}$ is the inner diameter of stator; and $l_{e f}$ is the effective stack length. Generally, the ranges of $k_{d}$ and $k_{e}$ are given by the following:

$$
\left\{\begin{array}{l}
k_{d}=0.9 \sim 0.93 \\
k_{e}=1.5 \sim 2.0 .
\end{array}\right.
$$

Ideally, the relationship between $I_{\mathrm{rms}}$ and $I_{m}$ is given by the following:

$$
I_{\mathrm{rms}}=\sqrt{\frac{1}{T} \int_{0}^{T} i^{2} d t}=\sqrt{\frac{1}{\theta_{c r}} 2 I_{m}^{2} \theta_{w}}
$$

where $T$ is the period of each cycle and $i$ is the instantaneous phase current. Based on the operating principle shown in Fig. 1(b), it yields $\theta_{w} / \theta_{c r}=1 / 3$. Hence, (3) can be rewritten as follows:

$$
k_{i}=\frac{I_{m}}{I_{\mathrm{rms}}}=\sqrt{\frac{3}{2}} .
$$

There is a wide range of possible combinations of the stator and rotor pole numbers for BDFDS machine design. In accordance with the basic operating principle of the BDFDS machine, the general relationships among stator pole number $N_{s}$, rotor pole number $N_{r}$ and phase number $m$ are given by the following:

$$
\left\{\begin{array}{l}
N_{s}=2 m k \\
N_{r}=N_{s} \pm 2 k
\end{array}\right.
$$

where $k$ is a positive integer. When the machine runs at the speed of $n$, the commutating frequency of any phase is $f_{p h}=$ $N_{r} n / 60$. To minimize the switching frequency, and hence the switching loss in power switches as well as the iron losses in poles and yokes, there should be as few rotor poles selected as possible. Therefore, there are usually fewer rotor poles than there are stator poles. To make the machine capable of starting itself in either the forward or reverse direction, the phase number should be equal to or greater than three. Thus, $N_{s} / N_{r}=6 / 4,8 / 6$, and $12 / 8$ are possible configurations of the BDFDS machine. As compared with the three-phase 6/4-pole machine, the three-phase 12/8-pole BDFDS machine possesses shorter flux paths in the yoke, resulting in lower iron losses. Moreover, because the flux per pole in the 12/8-pole machine is half of that in the 6/4-pole machine, the width of both the stator yoke and the teeth is almost one-half of that of the 6/4-pole one. This enables a larger inner stator diameter, and hence a larger rotor diameter; therefore, higher torque density can be achieved. Furthermore, a shorter width of stator teeth results in shorter end windings, leading to low winding resistance and less copper consumption. Hence, higher efficiency can be expected for the 12/8-pole BDFDS machine.

Note that the dc field winding is arranged in the space that has not been occupied by the armature winding. Thus, there is no conflict in space between these two windings. 


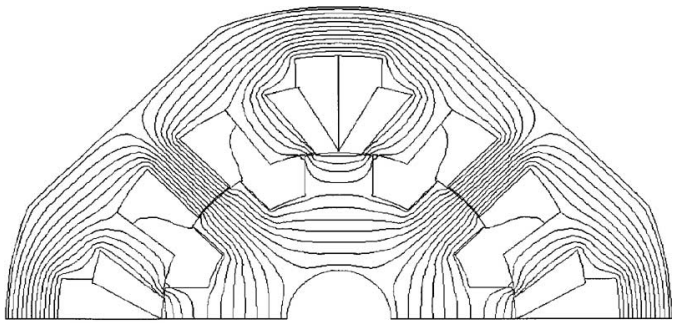

(a)

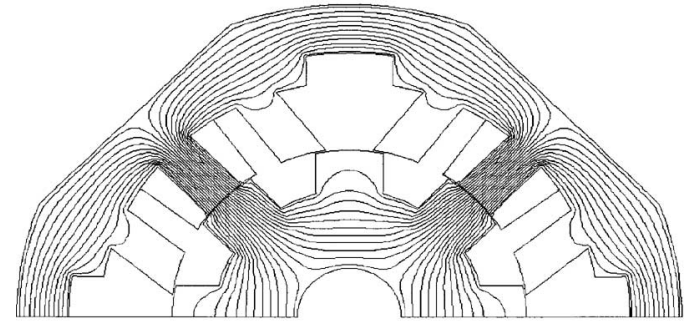

(b)

Fig. 2. Magnetic field distributions using FEM. (a) No load. (b) Armature current only.

\section{B. Design Procedure}

The design procedure of the proposed machine is outlined as follows.

Step 1) Based on the operating requirements, the rated speed, rated power, rated torque, and rated voltage of the machine are deduced.

Step 2) By using (1)-(5), the stator diameter, stack length, stator pole number, rotor pole number, armature winding turns, and field winding turns can be initialized.

Step 3) Determine the solution domain and the boundary conditions for finite-element analysis. Generate meshes automatically for the solution domain. Apply the finite-element method for electromagnetic field analysis.

Step 4) Evaluate the magnetic field distributions, air-gap flux linkages, and inductances. Hence, simulate the no-load EMF and torque performances.

Step 5) Modify the machine geometry and winding turns, and repeat Steps 3)-5) until the expected performances can be achieved.

\section{Finite-Element Analysis And System Modeling}

\section{A. Finite-Element Analysis}

When we use the finite-element method (FEM), we can analyze the static characteristics of the BDFDS machine. For simplicity, a 2-D FEM is adopted to determine the magnetic field distribution of the BDFDS machine.

Due to the periodic machine configuration, the region of interests for finite-element analysis is half of the whole machine cross section. The magnetic field distributions of the proposed BDFDS machine at different rotor positions and loads are analyzed. Fig. 2(a) shows the field produced by field current only, whereas Fig. 2(b) shows the field produced by the armature current of phase B only. It can be found that the flux path is

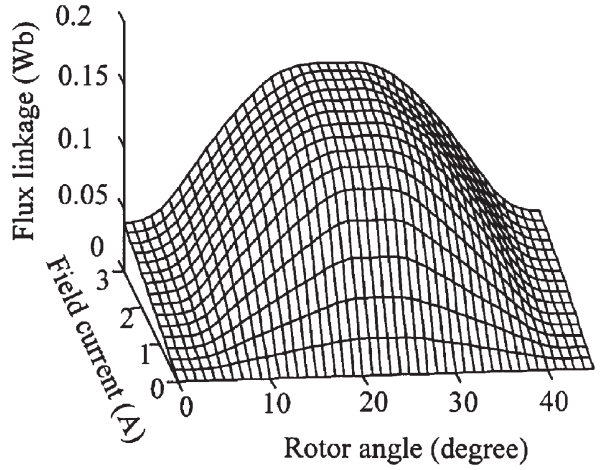

Fig. 3. Flux linkage at rated current using FEM

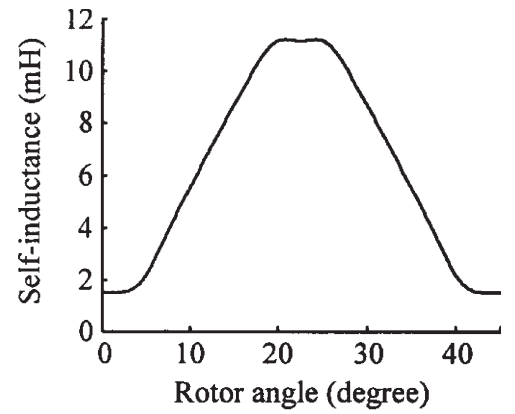

(a)

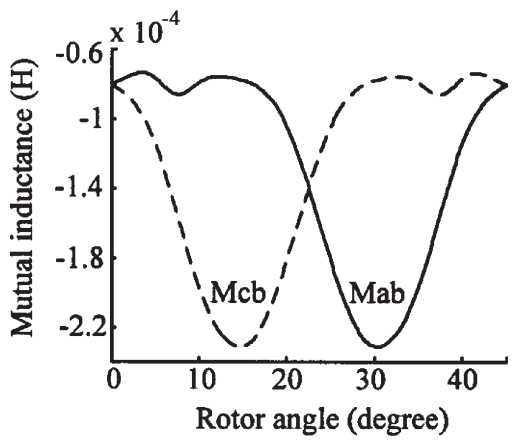

(b)

Fig. 4. Inductance characteristics at rated current using FEM. (a) Selfinductance. (b) Mutual inductance.

concentrated on the overlapping area between the stator and rotor teeth. For instance, because of small overlapping areas, there is severe magnetic saturation at the pole tips of phases A and C. Based on the finite-element analysis, the characteristics of the BDFDS machine, including the flux linkage, selfinductance, mutual inductance and back EMF, can be obtained. Flux linkage, which varies with the rotor angle and the field current, is shown in Fig. 3, and inductance characteristics are obtained as shown in Fig. 4.

\section{B. System Modeling}

The system matrix equation describing the three-phase 12/8-pole BDFDS machine is expressed as follows:

$$
\bar{U}=\bar{R} \bar{I}+d \bar{\Psi} / d t
$$

where $\bar{U}=\left[u_{a}, u_{b}, u_{c}, u_{f}\right]^{T}$ is the matrix of applied voltages; $u_{a}, u_{b}, u_{c}$ are the phase voltages; $u_{f}$ is the field voltage; 


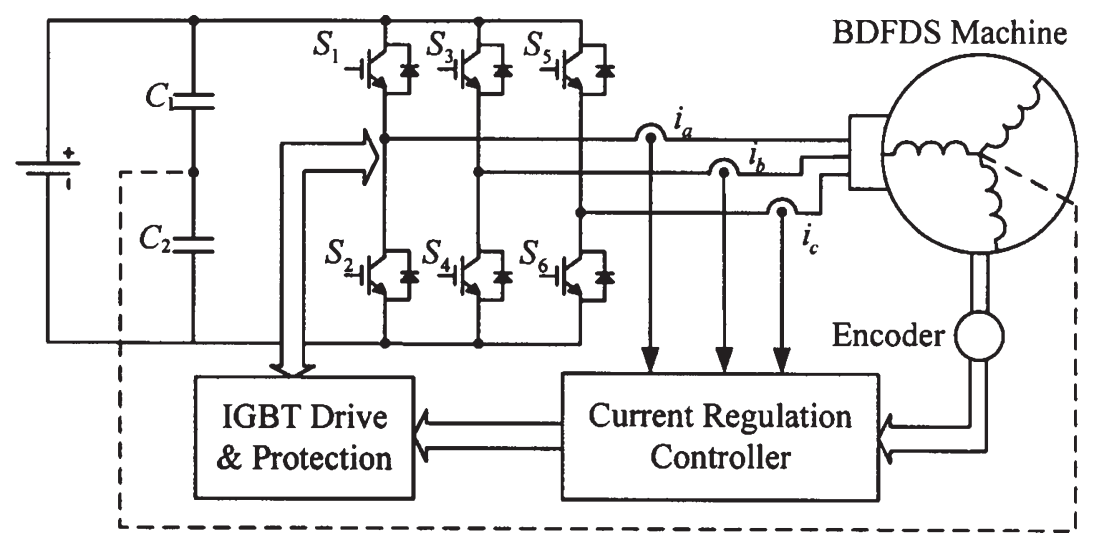

Fig. 5. System configuration.

$\bar{I}=\left[i_{a}, i_{b}, i_{c}, i_{f}\right]^{T}$ is the matrix of applied currents; $i_{a}, i_{b}$, $i_{c}$ are the phase currents; $i_{f}$ is the field current; $\bar{R}=$ $\operatorname{diag}\left[r_{a}, r_{b}, r_{c}, r_{f}\right]$ is the matrix of resistances; $r_{a}, r_{b}, r_{c}$ are the armature winding resistances; and $r_{f}$ is the field winding resistance. On the other hand, the matrix of inductances is given by the following:

$$
\bar{L}=\left[\begin{array}{cccc}
L_{a a} & M_{a b} & M_{a c} & M_{a f} \\
M_{b a} & L_{b b} & M_{b c} & M_{b f} \\
M_{c a} & M_{c b} & L_{c c} & M_{c f} \\
M_{f a} & M_{f b} & M_{f c} & L_{f f}
\end{array}\right]
$$

where $L_{a a}, L_{b b}, L_{c c}$ are the self-inductances of armature windings; $L_{f f}$ is the self-inductance of field winding; $M_{a b}$, $M_{b a}, M_{a c}, M_{c a}, M_{b c}, M_{c b}$ are the mutual inductances between armature windings; and $M_{a f}, M_{f a}, M_{b f}, M_{f b}, M_{c f}, M_{f c}$ are the mutual inductances between armature windings and field winding. The matrix of flux linkages $\bar{\Psi}=\bar{L} \bar{I}$ is given by the following:

$$
d \bar{\Psi} / d t=\bar{L}(d \bar{I} / d t)+(d \bar{L} / d t) \bar{I} .
$$

Thus, the system equation (6) can be rewritten as follows:

$$
\frac{d \bar{I}}{d t}=\bar{L}^{-1} \bar{U}-\bar{L}^{-1}\left(\bar{R}+\frac{d \bar{L}}{d \theta} \omega_{r}\right) \bar{I}
$$

where $\omega_{r}$ is the rotor speed, and $\theta$ is the rotor position in a mechanical degree. Energy stored in the magnetic field under current $\bar{I}$ can be expressed as $W_{f}=\bar{I}^{T} \bar{L} \bar{I} / 2$. When the iron loss is neglected, the input power of the machine can be described as follows:

$$
\begin{aligned}
\bar{I}^{T} \bar{U} & =\bar{I}^{T} \bar{R} \bar{I}+\bar{I}^{T} \bar{L} \frac{d \bar{I}}{d t}+\bar{I}^{T} \frac{d \bar{L}}{d t} \bar{I} \\
& =\bar{I}^{T} \bar{R} \bar{I}+\frac{1}{2} \bar{I}^{T} \frac{d \bar{L}}{d t} \bar{I}+\frac{d}{d t}\left(\frac{1}{2} \bar{I}^{T} \bar{L} \bar{I}\right) \\
& =\bar{I}^{T} \bar{R} \bar{I}+\frac{1}{2} \bar{I}^{T} \frac{d \bar{L}}{d \theta} \bar{I} \omega_{r}+\frac{d}{d t}\left(\frac{1}{2} \bar{I}^{T} \bar{L} \bar{I}\right) .
\end{aligned}
$$

Equation (10) can also be expressed as $P_{i n}=P_{c u}+T \omega_{r}+$ $d W_{f} / d t$, therefore, torque $T$ can be obtained as follows:

$$
T=\frac{1}{2} \bar{I}^{T} \frac{d \bar{L}}{d \theta} \bar{I} .
$$

\section{COMputer Simulation}

\section{A. Converter Configuration and Control Strategy}

To supply the BDFDS machine, a bipolar converter topology is preferred so as to make bidirectional current operation possible. Thus, there are two converter topologies in which the phase current can be controlled individually for bidirectional operation - the full-bridge converter and the half-bridge converter with split capacitors. The half-bridge converter is adopted as shown in Fig. 5, because it minimizes the number of power devices and each phase current can be independently controlled. The connection between the midpoint of the split capacitors and the neutral of motor windings, as shown by the dotted line in Fig. 5, is used to accommodate the transient current during the commutation period.

To produce maximum output torque and increase the system efficiency, the turn-on angle is specially chosen to ensure that the phase current is the maximum at the point when the phase flux linkage starts to increase. The turn-off angle is selected to achieve maximum torque. According to the flux linkage profiles $\left(\psi_{a}, \psi_{b}, \psi_{c}\right)$ shown in Fig. 6, the control logic for power switches of the converter $\left(S_{1}, S_{2}, S_{3}, S_{4}, S_{5}, S_{6}\right)$ can be determined. At any instant, two phases are energized and one phase is off. The three-phase command currents are depicted in Fig. 7, in which $\theta_{e}$ is the electrical angle, and the relation between electrical angle and mechanical angle is $\theta_{e}=N_{r} \theta$.

Note that although the control logic as described by Figs. 6 and 7 seems to be similar to that of the SR motor, there are two major differences: the proposed machine offers two conductive phases to produce torque, and the phase current is bidirectional.

\section{B. Simulation Results}

Based on the static characteristics shown in Figs. 3 and 4, motor performances are simulated using MATLAB/Simulink. The use of the MATLAB/Simulink environment takes advantages of easy programming, high flexibility and plentiful 


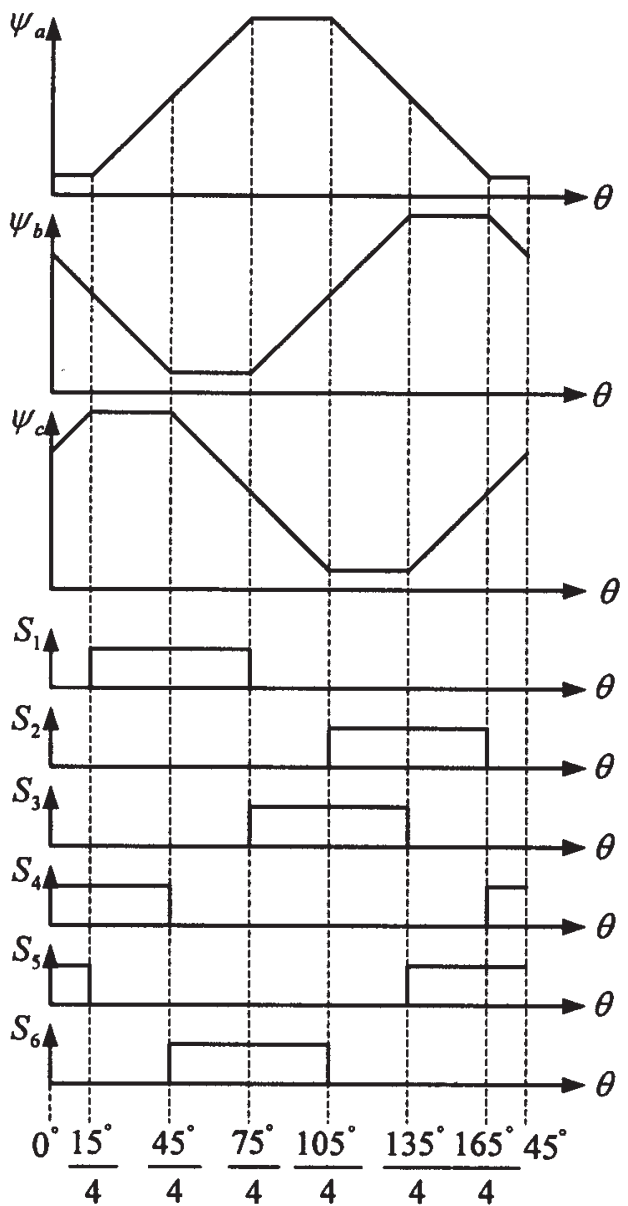

Fig. 6. Flux linkages and control logic.

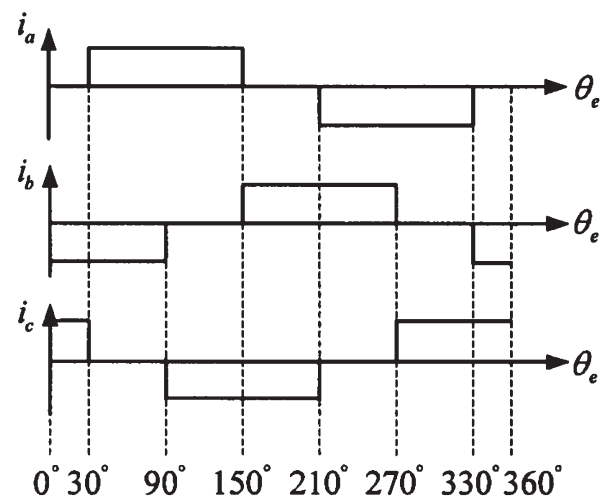

Fig. 7. Three-phase command currents.

toolboxes. The corresponding power system block is used to simulate the inverter and BDFDS machine together.

During simulation, the currents are solved by (9) after the voltages are determined by the rotor position. The instantaneous torque can be calculated by (11) when the currents are worked out. Torque control is achieved by changing the current reference. The corresponding control logic of those power switches is based on the encoder feedback signals that reflect the rotor position.

The total average torque $T_{\mathrm{av}}$, the instantaneous torque $T_{\text {inst }}$, the phase current $i_{a}$, and the flux $\phi_{a}$ under a steady state are simulated. Fig. 8 shows these waveforms when the BDFDS
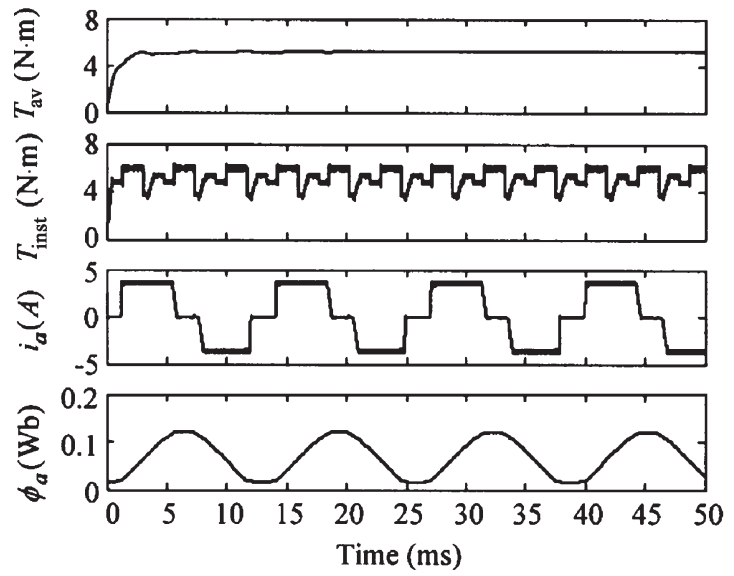

Fig. 8. Simulation results under a rated load at $600 \mathrm{r} / \mathrm{min}$.

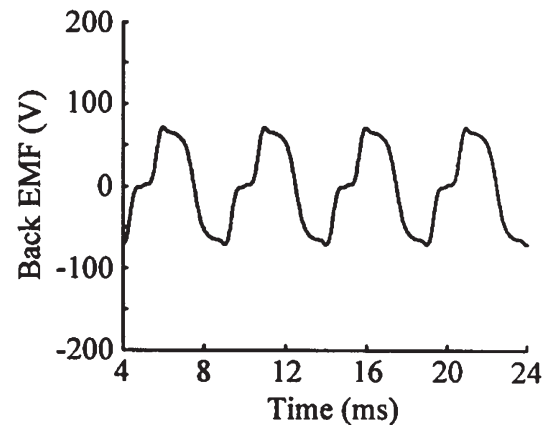

Fig. 9. Simulated no-load EMF waveform at rated speed.

TABLE I

SPECIFICATIONS OF A 12/8-POLE BDFDS MACHINE

\begin{tabular}{ll}
\hline Rated speed & $1500 \mathrm{r} / \mathrm{min}$ \\
Rated power & $750 \mathrm{~W}$ \\
Rated torque & $4.70 \mathrm{~N} \cdot \mathrm{m}$ \\
Rated phase voltage & $95 \mathrm{~V}$ \\
Stator inner diameter & $75 \mathrm{~mm}$ \\
Stator outer diameter & $140 \mathrm{~mm}$ \\
Stack length & $75 \mathrm{~mm}$ \\
Air-gap length & $0.3 \mathrm{~mm}$ \\
Stator pole arc & $15^{\circ}$ \\
Rotor pole arc & $22^{\circ}$ \\
Stator pole number & 12 \\
Rotor pole number & 8 \\
No. of turns of armature winding & 120 \\
No. of turns of field winding & 700 \\
\hline
\end{tabular}

machine is operated under a rated load of $4.70 \mathrm{~N} \cdot \mathrm{m}$ at a speed of $600 \mathrm{r} / \mathrm{min}$. It can be found that $T_{a v}$ keeps constant and that the current amplitude is effectively controlled. The simulated noload EMF waveform at a rated speed of $1500 \mathrm{r} / \mathrm{min}$ is shown in Fig. 9.

\section{IMPLEMENTATION AND EXPERIMENTAL VERIFICATION}

\section{A. Implementation}

A 12/8-pole BDFDS machine prototype is designed and built for verification. The corresponding specifications are listed in Table I. To verify the performance of the proposed machine, the hysteresis current control circuit and three-phase half-bridge converter are built. The insulated-gate bipolar transistor modules are used as switching devices in the converter. 


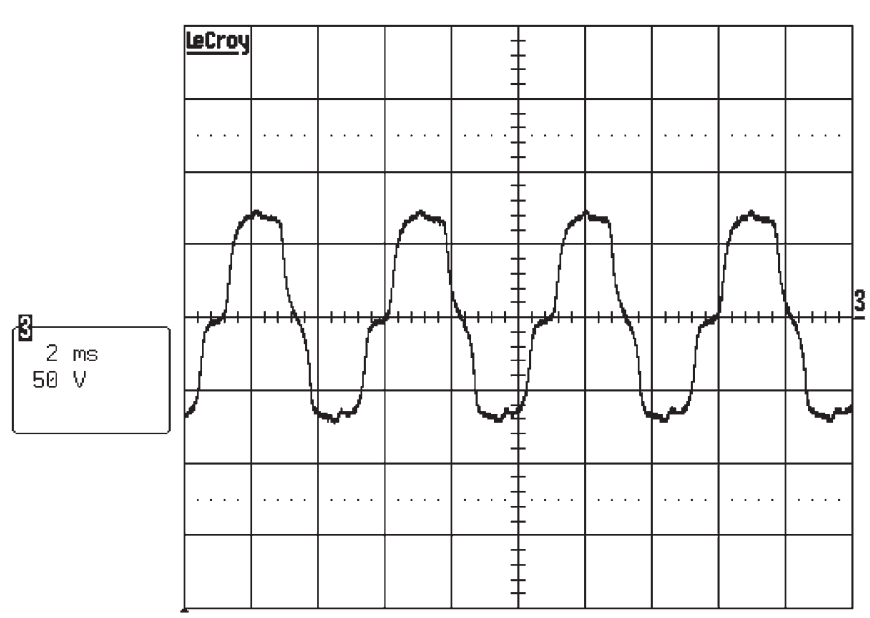

Fig. 10. Measured no-load EMF waveform at rated speed $(50 \mathrm{~V} / \mathrm{div}$, $2 \mathrm{~ms} / \mathrm{div})$.

The current control for the field winding of the BDFDS machine is straightforward simply by applying current chopping to a dc-dc converter. Hence, this field winding controller not only provides the necessary field excitation, but also offers flux weakening for high-speed constant-power operation and flux optimization for efficiency-optimizing operation.

In accordance with the operating principle of the BDFDS machine, the phase winding should be turned on or off at specific rotor positions. Hence, rotor position information is indispensable for proper operation of the BDFDS machine. In this paper, positions are measured by an optical encoder which produces 10000 pulses per revolution and is mounted with the machine in a coaxial way by a coupler.

The current is regulated by hysteresis control at low speed. To implement the current control, a controller based on dSPACE DS1104 R\&D controller board is built. The input commands to the controller are the phase current limit, turn-on angle and turnoff angle, while the feedback signals are the rotor position and phase currents. The phase currents are measured by the Halleffect current sensor LA25-NP from the LEM Corp., which measures bidirectional currents up to $25 \mathrm{~A}$ rms from dc to $150 \mathrm{kHz}$. Furthermore, the sensor can be mounted on the circuit board and the current ranges can be selected. Based on the control commands and the feedback current and rotor position, the controller produces the driving signals for the gate drivers of the converter.

The load of the tested machine is provided by a dc dynamometer. The operating point of the BDFDS machine can be changed by regulating the field current and the electronic load PLZ1003WH from KIKUSUI Electronics Corp. of the dc dynamometer.

\section{B. Experimental Results}

Fig. 10 shows the measured no-load EMF waveform at a rated speed of $1500 \mathrm{r} / \mathrm{min}$. We can see that it closely agrees with the simulated waveform shown in Fig. 9.

Under a rated load of $4.70 \mathrm{~N} \cdot \mathrm{m}$ and at the speed of $600 \mathrm{r} / \mathrm{min}$, the phase current, phase voltage and line-to-line voltages are measured. Fig. 11 shows the measured phase current

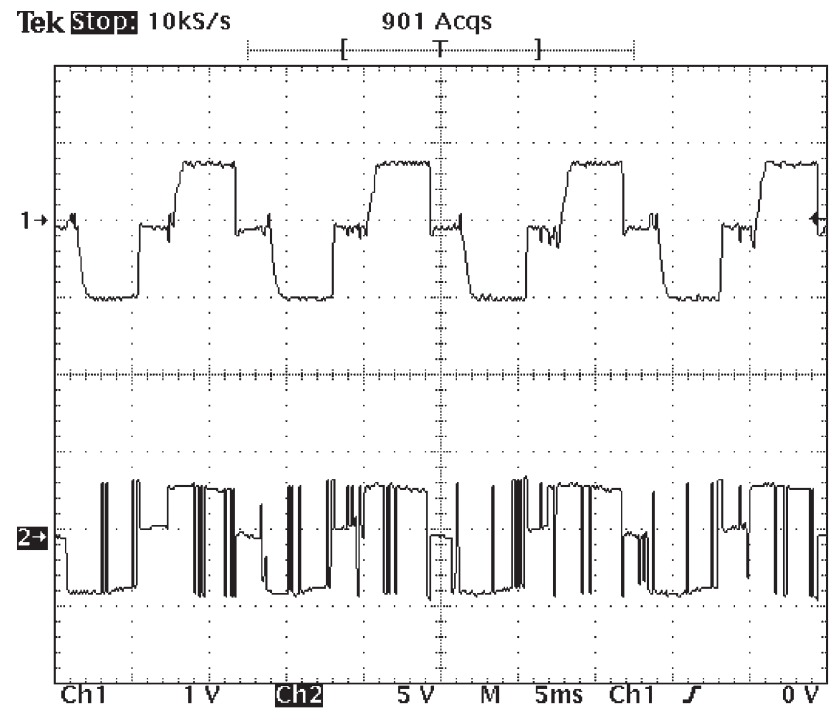

Fig. 11. Measured phase current (upper trace) and phase voltage (lower trace) waveforms under rated load (4.5 A/div, $50 \mathrm{~V} / \mathrm{div}, 5 \mathrm{~ms} / \mathrm{div})$.

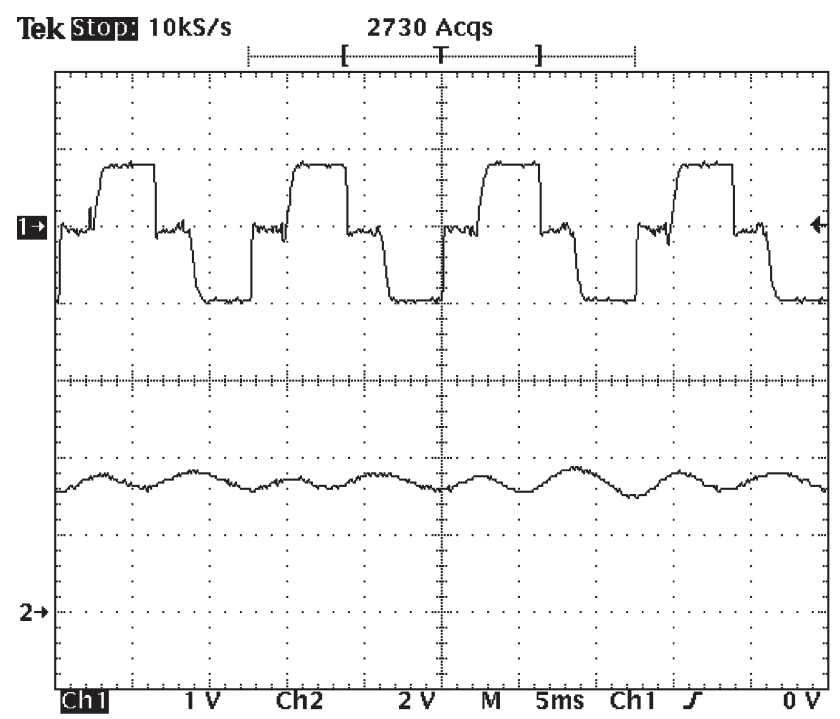

Fig. 12. Measured phase current (upper trace) and total torque (lower trace) waveforms under rated load ( $4.5 \mathrm{~A} / \mathrm{div}, 2.8 \mathrm{~N} \cdot \mathrm{m} / \mathrm{div}, 5 \mathrm{~ms} / \mathrm{div})$.

and phase voltage during hysteresis control operation. It can be found that the phase current is effectively controlled to follow a square waveform, and its amplitude is controlled to be constant. Both the phase current and total torques are also measured at the same condition. Fig. 12 shows these waveforms. It can be found that the torque ripple obtained from the measured torque waveform is only about $6 \%$.

Note that such a low torque ripple is due to the fact that the phase current is always synchronized with the back EMF, whereas the amplitude of phase current is virtually kept constant.

The phase current and the gating signals of relevant switches are also measured, as shown in Figs. 13 and 14. It is obvious that the measured current waveforms shown from Figs. 11-14 closely agree with the simulated current waveform shown in Fig. 8. It can also be found that the turn-on and turn-off angles well agree with the simulation results. 


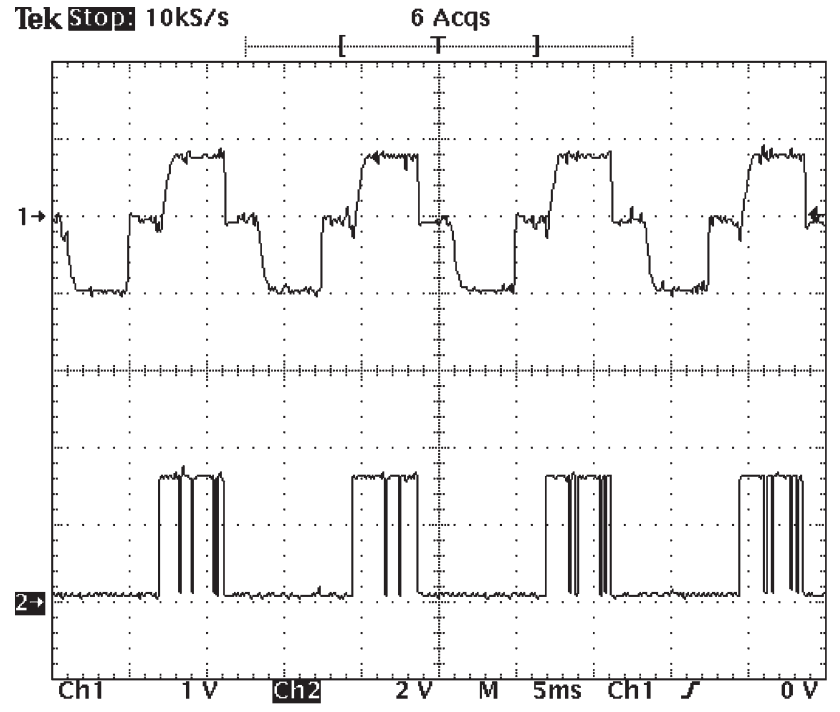

Fig. 13. Measured phase current (upper trace) and upper-switch gating signal (lower trace) waveforms (4.5 A/div, $2 \mathrm{~V} / \mathrm{div}, 5 \mathrm{~ms} /$ div).

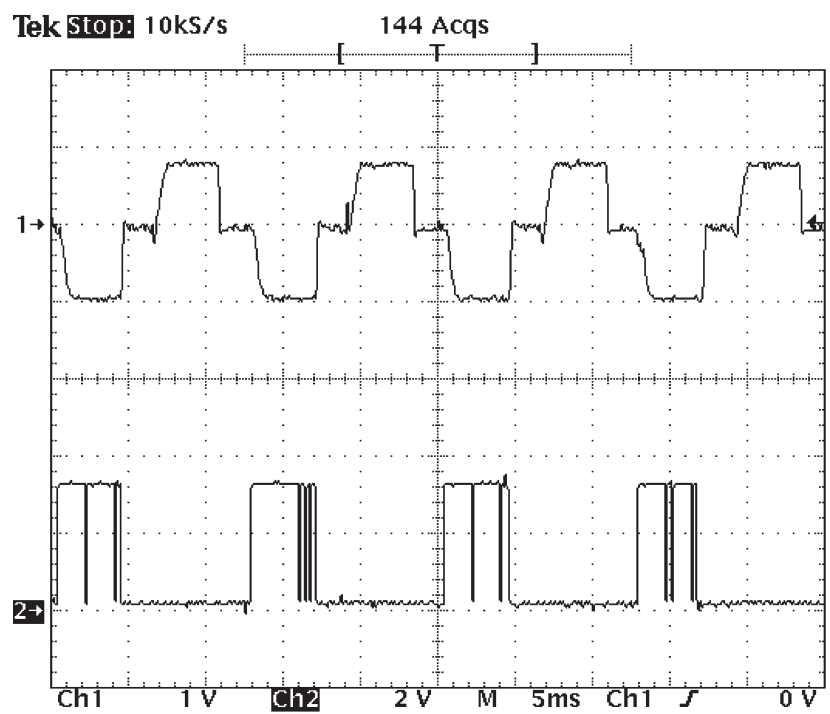

Fig. 14. Measured phase current (upper trace) and lower-switch gating signal (lower trace) waveforms $(4.5 \mathrm{~A} / \mathrm{div}, 2 \mathrm{~V} / \mathrm{div}, 5 \mathrm{~ms} / \mathrm{div})$.

Finally, the torque-speed characteristic is measured as shown in Fig. 15. It can be found that the BDFDS machine provides the constant torque when it is running below the rated speed. On the other hand, it keeps constant power above the rated speed. Furthermore, the system efficiency is measured as shown in Fig. 16. It indicates that the efficiency can maintain about $73 \%$ near the rated load, whereas efficiency is below $65 \%$ when the load is light. Moreover, by reducing the field current to realize flux weakening, the constant-power range is extended. Fig. 17 compares constant-power ranges at $I_{f}=1.0 \mathrm{~A}$ and $I_{f}=0.5 \mathrm{~A}$. The machine confirms that the constant-power range can be significantly extended by simply tuning the field current.

Note that the system efficiency of the BDFDS machine is relatively lower than a standard PM motor because use of dc field winding creates additional power loss. Nevertheless, such reduction of efficiency is well outweighed by the uniqueness of

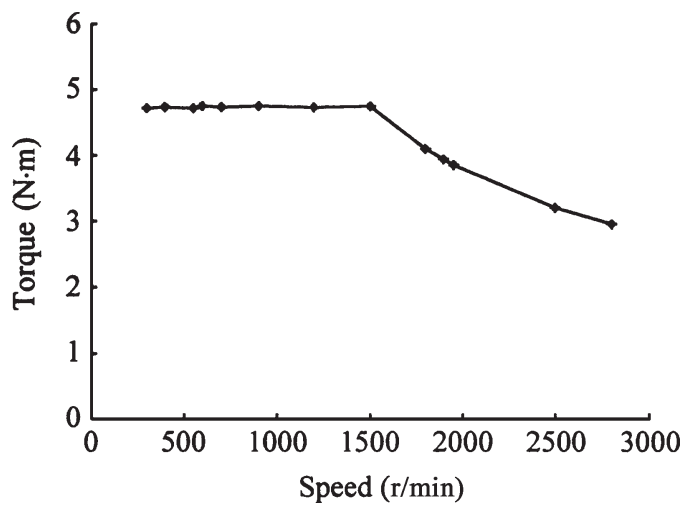

Fig. 15. Measured torque-speed characteristic.

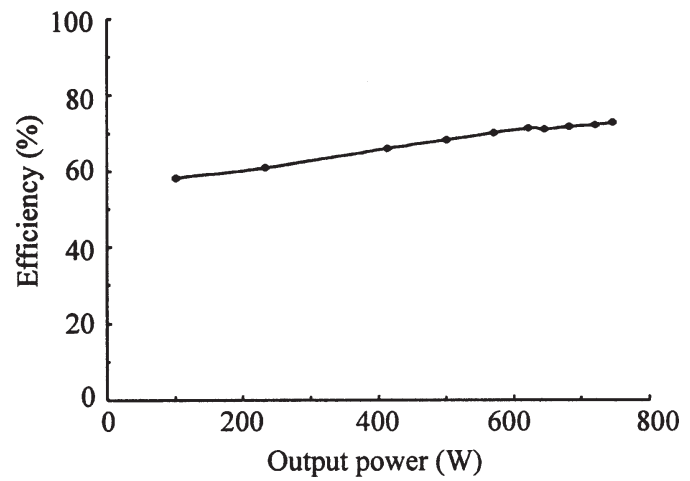

Fig. 16. Measured efficiency at rated speed and $I_{f}=1.0 \mathrm{~A}$.

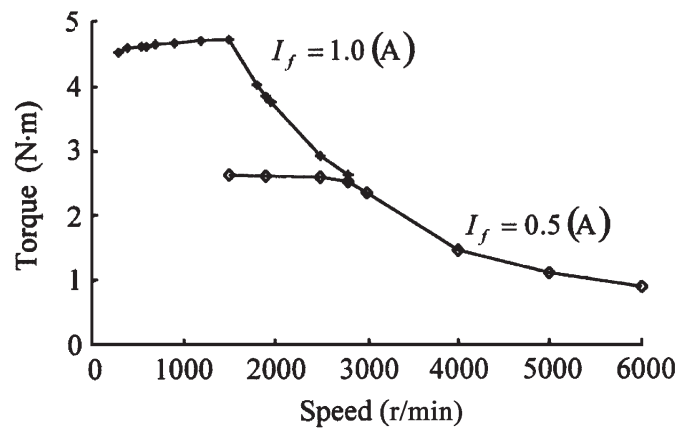

Fig. 17. Comparison of constant-power ranges at different field currents.

the effective flux control. which can extend the constant-power range significantly.

\section{CONCLUSION}

In this paper, the design, modeling, and analysis of a new BDFDS machine have been presented. The output power equation is analytically derived, and the initial calculation of machine dimensions and parameters are also discussed. By using finite element analysis, the field distributions of the BDFDS machine at different load and field current are obtained, in which the magnetic saturation and the coupling between armature current flux and field current flux are considered. Moreover, the static characteristics of the proposed machine are given. Based on the static characteristics, the system model can be established. Hence, the evaluation of system performances is conducted by computer simulation in which the simulation 
model combines the machine with a three-phase half-bridge converter. Furthermore, a 12/8-pole BDFDS machine is designed and built for verification. A drive system employing this new machine is prototyped and evaluated experimentally. The experimental results well agree with the theoretical analyses.

\section{REFERENCES}

[1] K. T. Chau and C. C. Chan, "Emerging energy-efficient technologies for hybrid electric vehicles," Proc. IEEE, vol. 95, no. 4, pp. 821-835, Apr. 2007.

[2] D.-H. Cho, H.-K. Jung, and C.-G. Lee, "Induction motor design for electric vehicle using a niching genetic algorithm," IEEE Trans. Ind. Appl., vol. 37, no. 4, pp. 994-999, Jul./Aug. 2001.

[3] D. Ishak, Z. Q. Zhu, and D. Howe, "Permanent-magnet brushless machines with unequal tooth widths and similar slot and pole numbers," IEEE Trans. Ind. Appl., vol. 41, no. 2, pp. 584-590, Mar./Apr. 2005.

[4] A. M. El-Refaie, T. M. Jahns, P. J. McCleer, and J. W. McKeever, "Experimental verification of optimal flux weakening in surface PM machines using concentrated windings," IEEE Trans. Ind. Appl., vol. 42, no. 2, pp. 443-453, Mar./Apr. 2006.

[5] K. T. Chau, D. Zhang, J. Z. Jiang, C. Liu, and Y. J. Zhang, "Design of a magnetic-geared outer-rotor permanent-magnet brushless motor for electric vehicles," IEEE Trans. Magn., vol. 43, no. 6, pp. 2504-2506, Mar./Apr. 2007.

[6] Z. Q. Zhu and D. Howe, "Electrical machines and drives for electric, hybrid, and fuel cell vehicles," Proc. IEEE, vol. 95, no. 4, pp. 746-765, Apr. 2007.

[7] K. M. Rahman, B. Fahimi, G. Suresh, A. V. Rajarathnam, and M. Ehsani, "Advantages of switched reluctance motor applications to EV and HEV: Design and control issues," IEEE Trans. Ind. Appl., vol. 36, no. 1, pp. 111121, Jan./Feb. 2000.

[8] S. S. Ramamurthy and J. C. Balda, "Sizing a switched reluctance motor for electric vehicles," IEEE Trans. Ind. Appl., vol. 37, no. 5, pp. 12561264, Sep./Oct. 2001.

[9] Y. F. Liao, F. Liang, and T. A. Lipo, "A novel permanent magnet motor with doubly salient structure," IEEE Trans. Ind. Appl., vol. 31, no. 5, pp. 1069-1078, Sep./Oct. 1995.
[10] R. Deodhar, S. Anderson, I. Boldea, and T. J. E. Miller, "The flux-reversal machine: A new brushless doubly-salient permanent-magnet machine," IEEE Trans. Ind. Appl., vol. 33, no. 4, pp. 925-934, Jul./Aug. 1997.

[11] M. Cheng, K. T. Chau, and C. C. Chan, "Design and analysis of a new doubly salient permanent magnet motor," IEEE Trans. Magn., vol. 37, no. 4, pp. 3012-3020, Jul. 2001.

[12] M. Cheng, Q. Sun, and E. Zhou, "New self-tuning fuzzy PI control of a novel doubly salient permanent-magnet motor drive," IEEE Trans. Ind. Electron., vol. 53, no. 3, pp. 814-821, Jun. 2006.

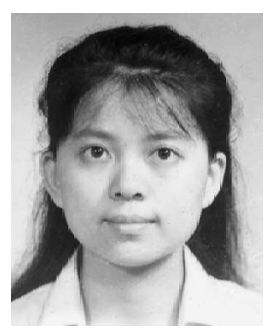

Ying Fan (M'07) received the B.Sc. (Eng.) and M.Sc. (Eng.) degrees from the Department of Electrical Engineering, Nanjing University of Astronautics and Aeronautics, Nanjing, China, in 1991 and 1996, respectively, and the Ph.D. degree in electrical and electronic engineering from The University of Hong Kong, Hong Kong, in 2006.

She is currently an Associate Professor and Deputy Dean of the Department of Electric Machine and Control, Southeast University, Nanjing. Her teaching and research interests focus on electric drives, electric vehicles, and wind power generation. She has published over 15 technical papers in these areas.

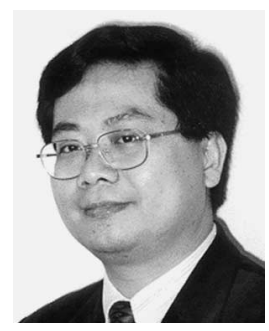

K. T. Chau (M'89-SM'04) received the first-class honors B.Sc. (Eng.), M.Phil., and Ph.D. degrees in electrical and electronic engineering from The University of Hong Kong, Hong Kong.

Currently, he is a Professor and Director of the International Research Center for Electric Vehicles at The University of Hong Kong.

His teaching and research interests focus on three main areas: electric drives, electric vehicles, and power electronics. He has published about 200 refereed technical papers and many industrial reports in these areas. He has also chaired and organized many international conferences. 